geographer and geologist would like to examine has been kept back although it turned out a success.

The publication of his book will, we fear, tend to detract from the reputation which $\mathrm{Mr}$. Borchgrevink has unquestionably merited by his organising power, his invincible perseverance and his successful completion of a considerable task. Had he been content to leave the the discussion of matters which he did not understand to the skilled members of his staff, and had he encouraged them to discuss and describe their observations, his expedition would have redounded to his credit in scientific circles, as well as amongst lovers of adventure. We believe that the extensive collections are being examined and described by specialists in the British Museum; and we hope that the magnetic and meteorological work will also be discussed by experts and published in detail. Some results in an unreduced form are given in the appendix, the most important being $\mathrm{Mr}$. Louis Bernacchi's excellent summary of the meteorological and magnetic observations, which is somewhat fuller than that published previously in the Geographical Journal.

It is painful to us to be obliged to touch on the limitations of a strong and courageous explorer, but we
Guinea, and leaves the earth in long. $156^{\circ} 58^{\prime}$ E., lat. $12^{\circ} 50^{\prime} \mathrm{S}$. (See accompanying map.)

While the weather prospects at most of the possible stations of observation are, unfortunately, not of the best, there is sufficient encouragement in the meteorological statistics to hope that records of the phenomena will be secured at at least one place.

In Mauritius, in the neighbourhood of the Royal Alfred Observatory, where the duration of totality is $3 \mathrm{~m}$. $35 \mathrm{~s}$., the chances of fine weather at eclipse time are very hopeful. Mr. Claxton, the director of the Ubservatory, states that on only two occasions since 1874 has the sky been overcast at 9 a.m. on May 18 , on sixteen occasions it has been less than half covered, and on nine occasions practically cloudless (Journal of the Brit. Ast. Assoc., vol. xi. p. 121).

In the Malay Archipelago, where the maximum duration of totality on the central line is nearly $6 \frac{1}{2}$ minutes, the weather prospects are not quite so good. At Padang, on the west coast of Sumatra, which is one of the most accessible and otherwise most suitable stations, the percentage clearness during $\mathrm{May}$ is only 28, as against 50 per cent. for the Makassar Strait between Borneo and Celebes (NATURE, vol. lxiii. p. 163).

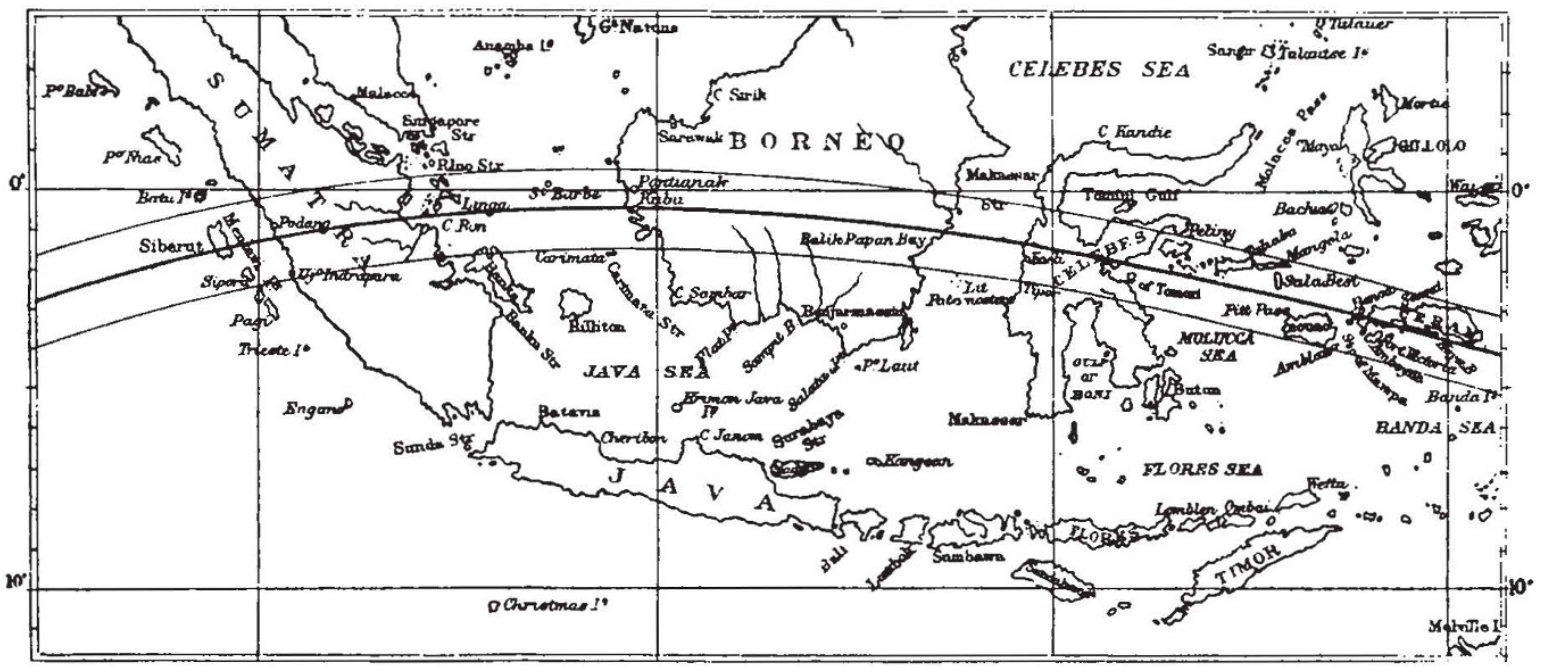

Part of the path of the moon's shadow during the total sslar eclipse of May 17-18, 190x. Reproduce from the Nautical Almanac Circular, No. 18 .

cannot pass by without protest so striking an instance of the inability of an unscientific chief to appreciate the nature of the problems which his scientific subordinates are investigating or the results they obtain.

\section{THE TOTAL ECLIPSE OF THE SUN,} $M A Y$ I8, 1901 .

THE approaching total eclipse of the sun is a notable one, not only on account of the unusually long duration of totality at the most favoured stations, but also because it occurs very near a time of minimum sun-spots. An exceptionally good opportunity of study. ing the corona at an important phase of the solar period is thus afforded, provided always that the sky is un. clouded at the critical times.

The shadow strikes the earth a little to the south-west of Madagascar, traverses a north-easterly path across the Indian Ocean, passing over Mauritius and entering Sumatra near Padang, continues eastward across the southern part of Borneo, deviates to the south-east through the Celebes and the southern part of New No. 1637 , voL. 63$]$
In these circumstances, it seems particularly desirable that the observers should be as widely distributed as possible, so as to diminish the risk of total failure to secure observations. This multiplication of stations, however, is rendered impracticable in this instance by the comparatively small number of astronomers at liberty to undertake the long voyage involved, and to some extent also by other causes, not among the least forcible being the undesirable presence of savage races at some places near the central line.

Arrangements have been made by the Joint Permanent Eclipse Committee of the Royal and Royal Astronomical Societies to attempt to secure observations at Padang and Mauritius. At the former station will be Mr. Newall and Mr. Dyson, who will be joined by Mr. Atkinson as a volunteer, and at the latter Mr. Maunder will work in conjunction with $\mathrm{Mr}$. Claxton. While it is to be regretted that other British observers of experience do not find themselves in a position to join the expeditions, there is consolation in the fact that parties from other countries have arranged to make observations. We understand that Holland will be represented by an expedition under Dr. Nÿland, of Utrecht, who will be 
accompanied by W. H. Julius and W. H. Wilterdinck, of Leiden, and will probably make Padang his headquarters. Somewhere in the neighbourhood of Padang, also, the American astronomers, Prof. Barnard and Prof. Todd, together with a party from the Washington Observatory, and another party from the Lick Observatory, are expected to set up their instruments. Prof. Campbell has selected Mr. C. D. Perrine to take charge of the expedition from the Lick Observatory, and this observer will be accompanied by Mr. R. E. Curtiss, of the Observatory at Berkeley; the expenses of the expedition will be defrayed by the well-known liberal benefactor to science, Mr. W. H. Crocker, of San Francisco. The Observatory has further learned, through Father Cortie, that certain members of the Calcutta Jesuit Mission will also go to Padang to observe the eclipse.

The most direct route to Padang from Europe is by the Rotterdam-Lloyd line of steamers ; a steamer leaving Southampton on April 9 and Marseilles on April 18 is due at Padang on May 12, and there is a return steamer on May 24, due at Marseilles on June I8. Return tickets at greatly reduced rates may be obtained through the British Astronomical Association.

As to the work to be undertaken, the great duration of totality emphatically demands that almost every effort should be directed towards the corona. Indeed, the study of the chromosphere and prominences during eclipses may well be considered to have reached a halting-place, so that in any case the study of these appendages would be considered of secondary importance. The great success which has attended the observation of recent eclipses has in some degree placed observation ahead of solar theory, and it is perhaps for this reason that most of the observations which, we understand, are to be undertaken are along familiar lines. To a certain extent this is, of course, inevitable, for it is always rightly regarded as a prime duty to record the phenomena as completely as possible.

Adequate provision is made for securing pictorial records of the corona. Some of these will be on a large scale to show the finer details of the lower reaches, and others on a smaller scale to depict the extensions seen with the naked eye. Messrs. Maunder and Claxton will utilise the photoheliograph of the Mauritius Observatory, giving pictures of the sun nearly 8 inches in diameter, and in addition will be provided with a 4 -inch coronagraph fitted with a negative enlarging lens to give images 2 inches in diameter; the long extensions will be specially attacked with a 4 -inch Dallmeyer R.R. lens of 32 inches focus.

At Padang, Mr. Dyson will erect the Thompson photoheliograph of 9 inches aperture, which was successfully employed by the Astronomer Royal in India and Portugal, the photographs being enlarged by a magnifier to a scale of 4 inches to the sun's diameter. The same observer will also take charge of a double camera with 4 -inch lenses of relatively short focus to grasp the feeble rays of the longer streamers.

It is probable that Prof. Barnard's instrument will be the coronagraph of $6 \mathrm{I}$ feet focus, with which he obtained such admirable photographs of the prominences and inner corona last May. Prof. Todd will again employ his wholesale method of obtaining photographs with cameras in which the exposures are given and plates changed automatically. Coronagraphs of 33 feet 3 inches and 5 -feet focus will form part of the equipment of the Jesuit Mission.

For the spectroscopic records, Mr. Maunder is provided with the 2 -inch prismatic camera with which $\mathrm{Mr}$. Evershed secured valuable photographs during the eclipse of 1898 . With this type of instrument, the principles of which are now sufficiently familiar to render a description superfluous, the spectra of both corona and chromosphere are recorded in the most complete manner. A modified prismatic camera, in the form of an objective grating, will be employed by Mr. Newall in an attempt to photograph the coronal rings. Mr. Dyson will again employ the two slit spectroscopes belonging to Captain Hills, which were used in India and Portugal, one of them being specially adapted for the ultra-violet spectrum. Another important spectroscope will be the prismatic camera forming part of Dr. Nÿland's equipment ; this consists of a 6-inch objective and two prisms of $45^{\circ}$, thus duplicating one of the instruments employed in the last two eclipses by Sir Norman Lockyer. The Jesuit Mission will investigate the spectroscopic phenomena with a Rowland concave grating of 36 inches focus, and a prismatic camera of 33 inches focus.

In the case of the slit spectroscopes and the objective grating, the long duration of totality will obviously be an immense advantage, and it is very desirable also that the experiment of giving very long exposures with the prismatic cameras should be made.

Among the more special inquiries, Mr. Newall will again attempt to investigate the rotation of the corona, and also to obtain photographs of the corona in polarised light. The first of these observations is a particularly delicate one, depending for its success on photographically recording the coronal spectrum with sufficient dispersion to exhibit the minute displacements of the bright lines produced by the rotation. The long duration of totality is especially favourable for this observation, but, on the other hand, there is evidence that at the time of sun-spot minimum the coronal lines are of but feeble intensity. Success is therefore by no means assured, but the slit spectroscope to be employed in the experiment is one of great efficiency and convenience, and the attempt is well worth making.

The study of the polarisation of the coronal light is also of some importance. The luminosity of the corona, apart from that due to the luminous gases of the inner corona, has been ascribed to the reflection of solar light by the small particles of which it is supposed to consist, and to the direct emission of light by such particles rendered incandescent by solar radiation. The bolometric observations of Prof. Langley's party at the last eclipse, however, led to the conclusion that the corona appears "neither to reflect much light from the sun, nor, chiefly by virtue of a high temperature, to give light of its own, but seems rather to be giving light in a manner not associated with high temperature" (NATURE, vol. Ixiii. p. 67). On the other hand, Mr. Newall, during the same eclipse, found a marked polarisation of the coronal light, indicating that a considerable proportion of the light is reflected. The accumulation of additional data bearing on the origin of the light of the corona, therefore, seems very desirable.

The fact that a British man-of-war will be sent to Padang to render assistance to Messrs. Dyson and Newall is a sufficient guarantee that an adequate record of the general phenomena of the eclipse will be made.

A. FOWLER.

\section{RED RAIN.}

$A \mathrm{~N}$ unusual, though it can scarcely be called a rare, meteorological phenomenon is reported from Italy, and has been made the subject of much highly coloured descriptive writing in the daily Press. The plain facts are thus given by Reuter's correspondent in Palermo in a telegram dated March Io:

"Since last night a dense lurid cloud has hung over this town. The sky appears of a sinister blood red hue, and a strong south wind is blowing. The drops of rain

$$
\text { No. } 1637 \text {, voL. 63] }
$$

